\title{
EFFECTIVENESS AND SAFETY OF ABATACEPT FOR 24 MONTHS FOR TREATING PATIENTS WITH PRIMARY SJOGREN'S SYNDROME (PSS)
}

Adriana Cristiane Machado (UNISA, SAO PAULO , SP, Brasil), Tania Fidelix (UNIFESP, SAO PAULO , SP, Brasil), Laura Caldas Santos (UNIFESP, SAO PAULO, SP, Brasil), Ilda Lekwitch Zveibil (UNISA, SAO PAULO , SP, Brasil), Simone Barbosa Soares (UNISA, SAO PAULO , SP, Brasil), André Felipe Gasparini (UNISA, SAO PAULO , SP, Brasil), Juliana Venturini Augusto (UNISA, SAO PAULO , SP, Brasil), Nelson Carvas Junior (UNIP, SAO PAULO , SP, Brasil), Virginia Fernandes Moça Trevisani (UNISA/UNIFESP, SAO PAULO , SP, Brasil)

\section{BACKGROUND}

Primary Sjögren's syndrome (SSp) is a systemic autoimmune disease concerning the exocrine glands and internal organs. The objective of this trial was to evaluate effectiveness and safety of abatacept for 24 months in the treatment of pSS.

\section{MATERIALS AND METHODS}

This was observational prospective study for 24 months, included 11 patients that filled the AmericanEuropean Consensus Criteria (2002). Patients received abatacept according the weight. It was evaluated Sjögren's syndrome disease activity index (ESSDAI), salivary flow with no stimulation for 15 minutes, Schimer's ophthalmologic evaluation tests, Ocular Staining Score (OSS) e Break up time, quality of life by Medical Outcome Survey Short Form 36 (SF-36) and fatigue by FACIT Fatigue - The Functional Assessment of Chronic Illness Therapy. For statistical analysis was used the Wilcoxon's test for related samples and $t$ test of Student to paired samples.

\section{RESULTS}

This study was constituted from 11 women between the ages 25 to 81 years (average: $53.73+$ +/ 15.07 years), being the majority afro-descendant women (54.5\%). Of this total, $90.9 \%$ presented positive antinuclear antibody (ANA), $81.8 \%$ positive anti/SSA, and $90.9 \%$ positive rheumatoid factor. In relation to ESSDAI, $81.8 \%$ of the participants presented scores greater than 5 . There was a statistically significant reduction in the ESSDAI IC $2.99[-0.49 ; 7.99](p=0.013)$. Between the sub items of the ESSDAI, the ones that demonstrated the greatest modifications were articular and glandular. There was a significant increase in the salivary flow of the participants (dif = -0.90; IC-95\%: -1.50; -0.50) after 24 months of treatment. Although we did not find significant effects in the ophthalmologic examination, there was a marginal effect on the left eye Break up time scale $(p=0.078)$. In the SF36 only in the Limitation for Emotional Aspects sub scale reported significant improvement (dif $=36.4$; IC95\%: $-67.1 ;-5.57 ; p=0.025$ ), and FACIT presented no evidences of significant changes between pre and post treatment $p=0.356$.

\section{CONCLUSION}

The study demonstrates limitations due to the few number of patients included and for being an open study not controlled, but we observed a statistically significant reduction in the ESSDAI, increase in the salivary flow and in the sub scale Limitation for Emotional Aspects of the SF36, indicating a positive effect in the disease. 